\title{
The concept of identity: \\ from philosophy to cell biology and back
}

\author{
Mircea Leabu' ${ }^{1}$ Kei Sasaki²
}

1 Victor Babeș National Institute of Pathology, Bucharest, Romania

2 Hokkaido University, Sapporo, Japan

\begin{abstract}
Life represents a very complex phenomenon based on the organization and functions of cells, the elementary units of any living structure. The proper functioning of every cell in an organism assures its health. In addition, proper functioning also means the great ability of cells to adapt to changes in the environment and survive to the advantage of the organism they belong to. Sometimes, the functions of some cells can be so affected by certain stressors that they can deviate from a normal to a pathological state. Proper functioning of the cell is determined by its identity, which if changed can often induce pathology. This is the underlying reason for our interest in cell identity determination, increasingly critical for our understanding of cell biology and medicine. In this paper, we aim to analyze the concept of identity in general terms, starting with its approaches in philosophy and switching toward its practical, biological application in cell identity. We will advocate the need to balance various views on the concept of identity in order to find solutions in approaching cell identity.
\end{abstract}

\section{Key words:}

sameness, uniqueness, group identity, personal identity, genidentity, diachronic identity, organelle identity, super-enhancers, stretch enhancers, micro-RNA

\author{
Article info \\ Received: $\quad 16$ June 2020 \\ Accepted: $\quad 12$ September 2020 \\ Available online: 20 October 2020
}

DOI

10:47570/joci.2020.002

JoCl year 1, vol. 1, p. 0017-0029, October, 20, 2020

\section{Corresponding author:}

mircea.leabu@ivb.ro

Both authors have equal contribution to the manuscript. 


\section{Introduction}

Cell identity becomes a concept of increasing critical significance for both physiology and pathology. Within the complexity of an organism, the normal behavior often (if not always) depends on the proper functioning of any cell, while a pathology also often (if not always) develops when a single cell is failing to function properly. Moreover, this overlaps the great ability of cells to adapt to a large spectrum of demands and stress events. This reason justifies our need to identify the moment when a cell loses its identity, becoming dangerous for the system it belongs to. Therefore, the concept of identity currently needs to be approached in a more careful manner in cell biology and medicine.

Over a long period of time, during human development and evolution, the concept of identity represented a challenging issue.

Philosophy was the first to raise awareness regarding this concept, and it can be traced back to ancient times. On the one hand, the identity was analyzed in terms of sameness. On the other hand, the identity was analyzed in terms of uniqueness. Paradoxically or not, both types of analyses make sense.

It is a very difficult task to try and untangle the complexity of identity as concept. We do not claim to intend to do this however, we will try to interpret this term in the context of cell identity in a practical manner, in order for it to become useful in the context of biologic and medical sciences, and for a better cell understanding.

This Journal aims to do the same: debate, analyze and understand the concept of cell identity.

Conversely, this essay tries to identify and point out the pathways by which philosophy, social sciences and biology could potentiate each other for better understanding and use of the concept of identity in the contemporary society and knowledge. This is not a hubris, but a mere attempt, as people with limited knowledge of philosophy, social sciences, as well as cell biology and medicine.

\section{The concept of identity in philosophy}

There is a physical versus a metaphysical approach to the concept of identity in philosophy. In the context of this essay, we will tackle the physical approach, even though the metaphysical approach cannot be completely disregarded. However, our goal is not to expand our argumentation toward what Eric Olson pointed out: "What it takes for us to persist might depend on whether we are biological organisms, which we cannot know a priori. nd if there could be immaterial people, such as gods or angels, what it takes for them to persist might differ from what it takes for a human person to persist" (Olson, 2019). Therefore, from a philosophical point of view, the concept of identity could be analyzed in various terms: starting with its logical meaning (close to mathematics) as sameness between objects, facts, realities, to reach debates both on the individuality of every element (material or spiritual) of the universe, and on its uniqueness, even reaching metaphysical reasoning.

In this context, to talk about sameness or uniqueness of objects, facts, realities or creatures we need criteria to be considered. These criteria could unquestionably be organized as sets. There are sets of criteria useful in defining sameness and sets of criteria defining uniqueness. Could the same set of criteria be useful for both defining sameness and uniqueness? For example, eyes color could be a criterion of sameness, if we intend to compare people according to this feature, but it could also be a differentiation criterion between different people. We may group people according to this criterion.

Certainly, only one criterion is not enough to establish either sameness or uniqueness. Despite the sameness of people with blue eyes, they are different and even unique, because many criteria have to be considered when comparing them. Therefore, sameness and uniqueness are relative concepts. There are groups of criteria useful in sameness analysis, but other groups of criteria useful in establishing uniqueness. 


\section{Group identity}

In philosophy, the locution "criterion of identity" was coined by Gottlob Frege, in 1884, (Frege, 1950), and strongly dissected by Ludwig Wittgenstein (Wittgenstein, 1958), but its exact interpretation is still a matter of debate and so is its application in various contexts. Let us go over some approaches in order to analyze further them in the context of concept of identity in cell biology, in the next section.

One sentence could be Leibniz's Law, or the identity of indiscernibles principle: objects or entities having all their properties in common cannot be separate things (Wiggins, 1967; Noonan and Curtis, 2018). Another opinion to be considered could be the Axiom of Extensionality as criterion of identity for sets: "Sets are the same if and only if (iff) they have the same members." Davidson's criterion of event identity stipulates that events are the same iff they have the same causes and effects (Tiles, 1976). In a similar clarifying intention, Hume's principle or HP - a term coined by George Stephen Boolos states that "the number of $F s$ is equal to the number of $G s$ iff there is a one-to-one correspondence (a bijection) between the Fs and the Gs" (Boolos, 1990; Anderson and Zalta, 2004).

According to the aspects mentioned above, sameness implies group identity, while uniqueness refers to personal identity.

A very simple and intuitive example in order to understand the meaning of group identity could be regarding human beings. There are factors defining human beings. As a group, they have their own identity. However, in the group of human being elements (we mean every individual), there are factors defining distinctness. For example, there are human beings who are women, as well as human beings who are men. Both carry the identity of a human being, but some (the women) are different than the others (the men). The Stoics claimed that two different objects (things and, more so, beings) that have exactly the same properties possess "sameness", although due to "time" and "space", they can never be exactly the same. Pushing forward our rationale on this track, we may reach the concept of individual identity or personal identity.

\section{Personal identity}

When deciphering personal identity, we can appeal to an example from natural sciences (physics and chemistry). All atoms of a certain kind (all atoms of an element) are identical, they carry the identity of the chemical element, but each is different, it has its own identity, even because they do not occupy the same position in space or in a molecule. Moreover, there are many atoms of the same element in a specific substance (for instance, in a glucose molecule: six carbon atoms, six oxygen atoms and twelve hydrogen atoms). All of the atoms pertaining to the same element are both identical and different. Therefore, the atoms in a glucose molecule could be analyzed in terms of sameness, or in terms of uniqueness. Nothing paradoxical, but rationally explainable. In order to surpass this apparent conflict, we may consider the locution Composition as Identity, with its strong thesis: "the composition relation is strictly identical with the identity relation, viz. that the parts of a whole are literally (collectively) identical with the whole itself" (Noonan, 2018). For this discussion about identity as individuality, K. Lewin's concept of "Genidentity" (applied to both physics and biology by the coiner) might be of use and perhaps should be examined here (Lewin, 1922). The definition of "Genidentity" is permanence of an object in different moments of its existence instead of the changes that it undergoes (Lewin, 1922). For example, an embryo and an adult (me as an embryo and me as an adult) have "Genidentity" (Nicholson and Dupré, 2018). In other words, according to genidentity view, "the identity through time of an entity X is given by a well-identified series of continuous states of affairs" (Pradeu, 2018). These well-identified series, referred to as "genetic series", form what we may call a traceability of the identity, identity kept during the becoming of an individual. Therefore, in more general terms, the identity of a dynamic (by its nature) object (thing, creature) is a matter 
of diachronic identity. In his book "An essay concerning human understanding", published in 1690, John Locke warns us that "In the state of living creatures, their identity depends not on a mass of the same particles, but on something else" (Locke, 1690). What is this "something else" is still a matter of debate. The genetic series (of states in time) of an object (thing, creature), the continuously generated states in its becoming should, in a way, be this "something else". Hans Reichebach mentioned in "The direction of time", that "it is not necessary for physical identity that these states [different states in time] be exactly alike.

A human being is the same, identical person all the time, although the body grows and changes its chemical building blocks. A physics of things does not require a denial of time flow. Common sense, as well as science, agrees with this conception of Heraclitus." Further in the book, he specifies that "We apply the relation of genidentity only to events connected by a causal chain. If causal chains are open, it follows that any two different events that are genidentical are not simultaneous. This consequence endows genidentity with a certain similarity to identity" (Reichenbach, 1971). In this context, we should keep this in mind.

Personal identity or uniqueness of dynamic objects, facts, realities or creatures were also approached by philosophers introducing two terms: endurance (in space and, eventually, time for things, mainly), and perdurance (in time and also space, for events or processes). "Perdurance theorists, as Quine puts it, reject the point of view inherent in the tenses of our natural language. From that point of view persisting things endure and change through time, but do not extend through time, but only through space. Thus, persisting things are to be sharply distinguished from events or processes, which precisely do extend through time" (Noonan and Curtis, 2018).

In this context, a question arises: What about nuclear explosions? Are they extending in both space and time (as both cause and effect)? From a philosophical point of view, are they fit for endurance or perdurance? They are events carrying persisting things (radioactive atoms), but not permanently persisting things (considering the half time life parameter). So, endurance and perdurance could be considered as co-existing in a fourdimensional world defined by space-time feature.

What about in a world with more than four dimensions, or in one with two spatial dimensions, the third being time? This is beyond our intention (ability?) to currently find answers. However, endurance and perdurance co-existence has to be carefully considered for a cell during its life, including if we try to define its identity.

Finally, for our incursion in philosophical approach regarding concept of identity, we have to consider the persistence question, a question that is roughly formulated as follows: "what is necessary and sufficient for a past or future being to be someone existing now" (Olson, 2019). The question is the same for a being or every other existing object. To our goal, we may paraphrase the question as: what is necessary and sufficient for a cell to keep its identity, to be the same cell today as yesterday and to be the same tomorrow? The question refers to its significance in terms of a cell that switches from a normal one to a pathological form. The question could be more general, but in the context of this essay, it is as follows: What are the factors that makes each one of us be ourselves?

To conclude on the suggestive debates above, we may say that we have to like philosophy, although it seems to mainly dissect evidence (except metaphysical thinking). But because evidence is relative (think about the sensation felt by keeping the right and the left hand in cold and hot water, respectively, after placing them in same temperature water ), we think philosophy is necessary, not to seek for absolute and universal, but to became conscious that everything is relative. In addition, we need philosophy, because it teaches everybody to think. Therefore, meditating to the concept of identity, as philosophy dissects it, will be helpful in interpreting and defining the concept of identity in cell biology. 


\section{A view on the concept of identity in cell biology}

In order to understand cell biology, we have to integrate physics, chemistry, even mathematics (multiparametric mathematics, as well as statistics/applied probability), but something else too, we do not know what yet. For example, understanding organization and functions of a cell membrane or an endomembrane means to consider the complexity of its biochemical composition, the physical interrelationships between its biochemical components one by one or as a whole. All these are responsible for the functionality of the ultrastructure, in the context of the cell (we mean extending the relationship of the membrane chemical entities with elements inside and/or outside the cell). Simultaneously, all these features can qualify as criteria of identity for that membrane and they can define its uniqueness. Therefore, in cell biology, the concept of identity is similarly difficult or even more so than in philosophy or social sciences.

Before our quest to analyze cell identity, let us start with the concept of identity in philosophy of biology. In the context of our analysis, the opinions of a vital rationalist, Georges Canguilhem, are definitely useful. He insists on the identity of physiological (normal) versus pathological living structures, characterized by similarities, despite of the differences in the effect on the organism (Canguilhem, 1994). In fact, both normal and pathological events of life use the same biological mechanisms. In physiology, events occur when necessary, with needed intensity, in relation with appropriate partners, at the right moment and the right location. Moreover, Canguilhem sentenced that "The identity of the normal and the pathological is asserted as a gain in knowledge of the normal" (Canguilhem, 1978). According to our knowledge today, in a pure Aristotelian tradition, a healthy organism is similar to a virtuous human being. Pathology means vice. Pathology means disturbance in the continuous internal organization of a cell, a tissue, an organ or even an organism. David Hull considers internal organization as a condition to maintain the identity of a living structure, and affirms that "the overall organization of any entity can change but it cannot be disrupted abruptly" (Hull, 1992). In our opinion, this is right for any structure in order to keep its identity, not for a living structure alone.

Now, let us address and pay more attention to identity in cell biology.

\section{Organelle identity}

The progress of our knowledge about the cell organization and functions was due to the discovery of organelles. An organelle is defined as a morphological element of the cell displaying a peculiar architecture and carrying specific function(s), being produced by the cell through a complex biogenesis process. Nowadays, the identity of different organelles is clearly established, even though there are debates regarding elements in the organization of a cell whether to be defined as organelles or not. In our opinion, these debates could be easily overcome by simply applying the definition of the concept "organelle" to the morphological elements in discussion. A quite recent example is bringing lipid droplets at the level of an organelle (Martin and Parton, 2006; Fujimoto and Parton, 2011). Therefore, after a long period of time where lipid droplets were considered just cell inclusions, they were finally defined, by a rational argumentation, as organelle.

Nowadays, what is unanimously accepted by the scientists in the field as organelles is clearly identifiable in both morphological terms (structurally and ultra-structurally) and by their biochemical composition, molecular organization, and function(s). For example, a ribosome is an unmistakable morphological element in a cell, organized in a functional state by two subunits containing few, different molecules of RNA (ribosomal RNA rRNA), as well as proteins, dealing with protein biosynthesis. Even though in prokaryotes and eukaryotes the number of RNA molecules and proteins of each subunit is different (lower in prokaryotes than in eukaryotes), the ribosome is organized in both cells from two subunits that are separated when the organelle is not in function and joined, on a messenger RNA, when functional. The identity of a ribosome is, therefore, clear for cell biologists. No necessary changes should apply, except organelle number (hyperplasia), 
to ensure the needs of a cell. The ribosome remains identical, regardless of the protein produced. However, the amount of a protein produced, in a specific context, can only influence the ribosomes' number in a cell, but not their organization, nor their identity.

Similarly, even more complex organelles have a clear identity. They cannot be confused even though they contain the same types of biomolecules in their organization. We may consider as an argument two membrane-bound organelles, nucleus and mitochondrion, containing the same types of macromolecules (rightly in different amounts and organization). Despite a significant number of similarities that can be listed, the two organelles are easily identifiable as different. To argue this affirmation, we remind that both organelles are bounded by two membranes systems, both organelles contain similar types of macromolecules, such as DNA, RNA, proteins. However, the organization of these similar types of macromolecules is obviously different and this is enough to help us decipher them as different organelles. No minimally instructed person will mistake a nucleus for a mitochondrion. Even though, in specific contexts, the cell's needs, related to an organelle, impose some changes, these mean just hyperplasia or even hypertrophy of the organelle, without any alteration of its molecular organization, its basic morphology, and functions. These changes attract no confusion and the organelle identity, as well as its organization and function(s) stay clear.

Nevertheless, when we switch from organelle identity to cell identity, in order to clearly establish the second one, it is not an easy task at all, but this becomes increasingly important and critical in cell biology and medicine.

\section{Cell identity}

All cells of a multicellular organism carry the same genetic information. According of this reality, cells in an organism could be considered as accomplishing the sameness characteristics. All of them are a result of repetitive divisions of a single cell: a fertilized oocyte. However, the genetic information of a cell, in an organism, which are inherited from the fertilized oocyte, the first one producing the whole organism, represents just a potential. In the real life of the organism, during its growing from an embryo to a fetus to youngster to adult, the cells differentiate finalizing by using only a part of the genetic information. They develop a lot of phenotypes (from potential to real), necessary to accomplish specialized functions as individual cells, according to the needs of the tissue and organs they belong to, in order to assure their proper functionality and survival of the organism. Therefore, the cells travel the path from sameness to uniqueness. The initial, parental cell for all cells in an organism is a stem cell (being it totipotent, pluripotent, multipotent, oligopotent or unipotent) and the biological process creating specialized cells in an organism is referred to as differentiation. The path traversed by cells passes through a group identity (cells belonging to different types, such as epithelial cells, muscle cells, nervous cells etc.), still in the realm of sameness (according to Leibniz's Law that could be applicable for this case). However, this travel corresponds to the genidentity view as well: cells pass through a genetic series of different states in time, each generated by the previous one and being the precursor of a future one. This trip finishes as a personal identity for every individual cell (uniqueness) and not only because they are different in time and space.

Usually and for a long time, cell identity has been appreciated mainly by shape and other few morphological features. Now, these criteria for sameness are not enough for defining the identity of a cell, but they also work for a group identity characterization. In order to define the uniqueness of a cell, sets of criteria at molecular level are needed, usually, but not always, sets of macromolecules organizing cell membrane being in use. According to our knowledge today, we may affirm that a cell is what its membrane is. That is, what its membrane is in terms of molecular organization both qualitatively, and quantitatively. This is a claim that usually works, but it does not always work in cell biology. Sometimes, we have to consider criteria addressing molecular markers inside the 
cells. Moreover, there are paradoxical cases. Let us consider two cells looking obviously different, but for which we did not identify a set of criteria yet, at molecular level, differentiating their individual identity. If we thought normatively, we would logically expect to identify at least one molecule (preferably a macromolecule) in a cell that is different of all the other molecules of the other cell. If this expectation was not only rational, but also real, the identification of such molecule would be an extremely difficult task, on the one hand, and, on the other hand, it would not be, a priori, a proof of identity.

The task is even more difficult if the parameter useful in checking the cell identity is not a qualitative one, but it only works at a quantitative level. We refer to a macromolecule expressed at a specific level in a certain cell.

But if we were to consider the fact that many macromolecules express in a certain cell, at a specific level, in a specified moment (the concept of spatial-temporality in cell biology) to determine the best functionality of that cell, then defining the identity of a peculiar cell would become even more difficult. Again, the relativity of the truth becomes evident. However, we have to find solutions to practically solve the matter. Solutions could be offered by a balanced approach using a narrative method and a normative thinking simultaneously.

The cell is what it has to be in a specified context imposed by the environmental conditions. There are general criteria proving a cell identity (at least in terms of group identity) and specific criteria to define its "individual identity" (a term we suggest as an alternative in cell biology for "personal identity"). A cell is identical with itself, but permanently other cell, because it is alive. In order to address its identity, we can use the genidentity view. Life is a process and that means it is permanently changing, while every cell passes through what we call a genetic series. However, the usefulness of genidentity is not absolute. Sometimes, for various reasons, a cell can be hijacked out of its fate (designation). From a functional point of view, it becomes another cell. A well-documented example could be the process called epithelial-mesenchymal transition. This phenomenon is proved to occur in biological processes, such as development, wound healing and stem cell behavior, but it also contributes to pathological events such as fibrosis or cancer progression (Lamouille et al., 2014).

In this case, even though we may trace the history of cell life in a manner suggesting a genetic series, the identity of the cell is changed. Therefore, it is not an easy task to analyze and establish criteria of identity in cells' world, but it is necessary. Current works on cell biology knowledge deepening suggest that, in defining the identity of a cell, we need panels of (macro)molecules sometimes of different chemical nature. As mentioned above, any particular cell is a result of expressing a part of total genetic information, perfectly identical in all adult cells of an organism. However, proteins' expression (genetic information in use) in a cell is continuously dynamic, being a matter of bunch of information coming from the outside or the inside. This expression is under a strict control and careful modulation according to the external and internal context of a cell. Therefore, the identity of a cell could be established considering either the results of genetic information use (expressed proteins - types and quantities) to determine the right cell's function, or the factors controlling and modulating proteins' expression, or both.

Consequently, we may adapt the concluding question in the previous section. Here, the question is: what are the factors that make a cell be itself?

First of all, the cell is determined to be itself and to function according to its identity by the genetic information used by itself and by the spectrum of proteins it expresses. This is known for a very long period of time. And it has worked for a long time. However, our knowledge expanded significantly in cell biology and, currently, other factors controlling cell identity were also pointed out. Therefore, what a cell is, at a specific instant, depends on complex mechanisms of control, regulation, and modulation of its function and behavior, in a certain context. 


\section{DNA contribution to cell identity}

A primary control of cell identity is due to the organization of chromatin as heterochromatin or euchromatin (Greenstein and Al-Sady, 2019; Greenstein et al., 2018). By packing chromatin very tightly, heterochromatin avoids expression of genes that are not useful to any or other histological types of cell. We may quote here what very clearly and suggestively Greenstein and Al-Sady mentioned: "heterochromatin takes on a key function in the establishment and maintenance of cell identity", because "heterochromatin has evolved to regulate the genome in a large variety of ways" (Greenstein and Al-Sady, 2019). Beyond this chromatin organization, in terms of its packing, factors that control, regulate and modulate a cell behavior are either regions in chromatin, organizing super-enhancers or stretch enhancers (Hnisz et al., 2013; Khan et al., 2018), or products of gene transcription and expression such as RNA (micro RNAs - miRNAs, long noncoding RNAs - IncRNAs, or simple noncoding RNAs - ncRNA), transcriptional factors, epigenetic factors. Mechanisms of these pathways cross talk to do the best job in determining cell identity. The formation of heterochromatin domains in the right locations of chromosomes is critical for both genome integrity and determination of cell identity. There are many ways and mechanisms committed in this task and they are led by proteins and ncRNAs, triggering even epigenetically control for chromatin packing.

Nevertheless, the accessibility of transcription machineries to genes is not governed only by the balance between heterochromatin and euchromatin. Domains of chromatin and specific sequences of DNA act as transcriptional enhancers, driving gene expression. Large clusters of transcriptional enhancers were discovered acting as super-enhancers that control the expression of genes involved in determining cell identity (Hnisz et al., 2013). These super-enhancers show a higher activity and cell type specificity than stretch enhancers (large chromatin-defined regulatory regions, also acting in cell identity characterization) or individual enhancers (Khan et al., 2018).

In conclusion, DNA is critical in determining cell identity through its organization at chromosome level, but it can do nothing without cross-talking with the other factors involved in the control and regulation of gene expression.

\section{RNA contribution to cell identity}

The first type of RNA acting in cell identity determination is messenger RNA (mRNA). These RNA molecules result from processing a precursor-RNA by splicing, removing introns and keeping exons in the final mRNA. These RNA molecules are responsible for protein biosynthesis in the cytoplasm. Ribosomes translate information carried by mRNA codons in polypeptide chains that further built the functional proteins by appropriate folding.

For a long time, RNA fragments (such as introns and other transcription products that were not mRNA, rRNA or tRNA) were considered junk material, until miRNA functions were discovered. Most of these functions are controlling and regulation of a plethora of cellular processes. Some miRNAs regulate gene expression at a post-transcriptional level, through their ability to interact with mRNAs somewhere in the untranslated sequence at $3^{\prime}$ end (3'UTR), leading to the repression of translation (Filipowicz, 2005; Tomari and Zamore, 2005). This regulation of protein production controls and modulates cell behavior as a response to internal and external signals, and this is a dynamic way to "adapt cell identity" to the environment restrictions or internal needs, allowing the cell to survive.

Then again, by their complex binding features, IncRNAs can directly interact with proteins, other RNAs or DNA and can regulate gene expression at post-translational (protein function availability), post-transcriptional (RNA availability), and transcriptional (gene availability) levels (St Laurent G et al., 2015; Charles Richard and Eichhorn, 2018). These mechanisms governed by IncRNA represent other pathways to control cell identity.

Therefore, the products of DNA transcription have sensible functions in controlling 
genetic information use in a cell, by tuning protein expression and tuning cell identity as well. This is a biological way to tune what genidentity view defines as genetic series

(states in time of a cell).

\section{Protein contribution to cell identity}

There is a significant amount of proteins acting as regulators of gene expression according to the needs of a cell, referred to as transcription factors. Usually, they shuttle between cytosol and nucleus, being activated by several signaling events, in order to determine the cell to behave appropriately, considering the information received from environment or the internal needs. This is a simple manner to explain the cell's ability to adapt and survive. However, proteins expressed in a cell can all participate to cell identity determination; not qualitatively, but quantitative expression, and mainly the ratio they express one (anyone) versus another (whichever of the others). Obviously, such a descriptive manner to approach cell identity, by proteins input, is a very difficult one and practically not useful.

However, we have to keep this in mind. Sometimes, overexpression or lowering of protein expression, out of some limits, in a cell could affect so significantly its role and behavior and this could push it to become another cell and, most dangerously, a pathological one. Therefore, a right determination of cell identity is of high impact in cell biology, as well as in physiology and medicine.

We can say that the more active a cell is (so it has less heterochromatin and more genetic information in use), the more difficult it is for us to define its identity. A very active cell is like a good actor playing theatre. Such a cell has the ability to do a huge diversity of functions (as a hepatocyte can do, for example), just like a good actor can play a comedy, a drama or a tragedy, regardless of the role in these plays. Consequently, similarly to the actor being the same person, keeping his/her identity as a human being, the

Figure 1.

Suggestive quantity of putative factors needed to define cell identity. The pink areas show the extent to which candidates define the right panel of markers.

(A) A cell with a low quantity of genetic information used;

(B) A cell with a medium quantity of genetic information used;

(C) A cell with a high quantity of genetic information used to perform its functions. cell keeps its identity, but it adapts to the environmental signals and its own needs in order to survive and doing its best job in the interest of the tissue, the organ and the organism it belongs to.

To conclude, in the context of the commentaries above, we may understand that the factors controlling and determining a cell's identity have to be searched at the intersection of DNA, RNA and protein contributions (Fig. 1). This intersection represents a lower or a higher spectrum of macromolecules, according to the activity level of a cell (pink area in the figure). The more active a cell is, the more difficult it is to determine its identity by a right panel of markers (a complex panel including DNA, RNA and proteins).

We are afraid that no cell's identity can be determined by only one, unique factor: a unique gene, or (macro)molecule expressing only in that cell. Therefore, in order to decipher the identity of a cell, we have to adapt a pluralistic approach instead of a monistic one (Pradeu, 2016).

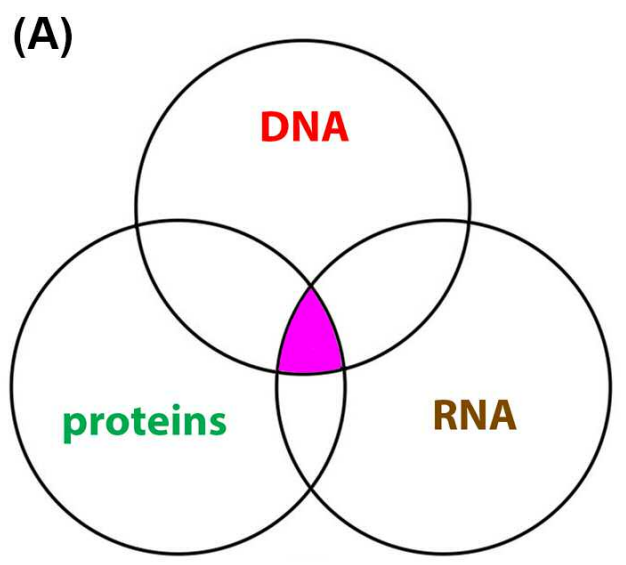

(B)

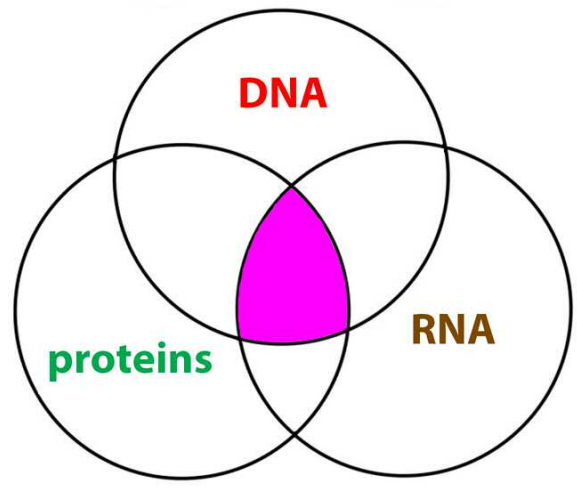

(C)

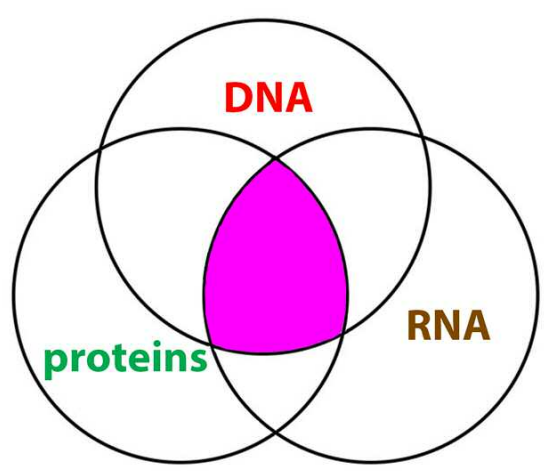




\section{Reciprocal potentiation of biological and philosophical concepts of identity}

In order to understand the concept of identity, we need wisdom. Wisdom is, or it has to

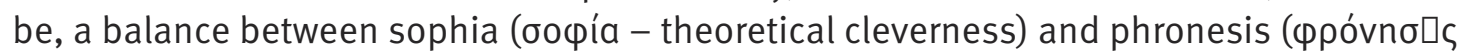
- practical cleverness). Theoretical cleverness help us in terms of a normative approach of cell identity, while practical cleverness enables us to pursue a narrative method. Despite what we know should be done theoretically, to practically define cell identity is far from easy, as it is to define the concept of identity in philosophy as well.

We may affirm that nature and reality are simple. Our perception of them and our manner to decipher them are complicated. At the moment, we understand an object, a creature, a fact, or a reality and its simplicity becomes evident. The goal of any research activity, including in cell biology, has to be the deciphering of the simplicity of things. However, in order to do this, we have to complicate ourselves first. For example, nothing is simpler, in our opinion, than the second principle of thermodynamics. To keep the order in this world, we need energy consuming. The more complex the system to be kept in order is, the more quantity of energy is required. Therefore, despite the simplicity of the entropy principle, its application to attain order in a complex system is not simple at all. Similarly, in cell biology we need to define the identity of a normally functioning cell in order to identify the deviations toward a pathological state. The earlier we identify the dangerous deviations from normal in a cell, the better for the medical act. This has to be the target of any biomedical research, and this has to be the goal in cell biology. Nevertheless, we advocate the run toward simplicity, not toward simplism. In "Perennial philosophy", Aldous Huxley warned us that "Nothing is more difficult than to be simple" (Huxley, 1947).

Addressing the concept of identity seems to be similar to the use of a definition of genus-differentia type. Group identity analysis establishes a genus (sameness for a family of objects), while personal/individual identity is similar to establishing the specific features (several differentiae, useful in extracting the individual from the genus as a peculiar object).

Moreover, the concept of identity cannot be approached as an absolute one. However, its relativeness does not overcome the rational limits. Therefore, a rock is the same object, whether it is dilated or contracted, because of the environmental temperature. It is also the same rock if it is lighted by a blue or a red light, even though our perception on it changes. It is still a rock, not a chameleon. Thus, identity, be it a group identity or a personal/individual identity, is not only a matter of perception, but also a matter of evident, intrinsic features. This is valid for the concept of identity both in a philosophical view and in a cell biology perspective.

Cells teach us that everything has to be considered in a permanent dynamic. The more complex the system is or it becomes, due to its dynamics, the more differentiae have to be identified in order to appropriately define its identity. In the context of cell identity, the genidentity view is necessary, but not sufficient in solving the issue. This is because sometimes, despite a cell appearing to follow a genetic series during its dynamic life, its identity can change for various reasons. These happen during cell differentiation in development, or other physiologic events, including regeneration, but sometimes these identity losses induce pathologies.

Therefore, according to our knowledge today, in order to establish cell identity, we need to seek criteria to arrange and clarify the matter.

\section{Conclusion}

We are personhoods permanently developing; we are permanently ourselves and "other" being simultaneously (both as body, and as mind): new molecules are permanently produced in our cells; biological processes in our cells are in a permanent dynamics (which means our cells are changing permanently, our knowledge and 
experience grow permanently). However, we cannot say that we lose our identity or that our cells lose their identity. There is a continuity in our identity, a persistence of our personhood despite of this permanent dynamic. The same goes for our cells, too. It is right to consider our cells keep their identities, despite permanent changes due to their metabolism, as long as they keep their normal behavior. If the row of different states in time (genidentity) keeps the cell function in normal limits, cell identity stays unchanged. However, there are contexts that push a cell toward an improper functioning, and this means cell identity is changed.

|These contexts need to be investigated and the deepening of our knowledge in detecting the limits between physiology and pathology in biology could be also useful in both philosophy and social sciences.

As a first approach, a cell identity is proved by its function. In a conference held at the Institute of Cellular Biology and Pathology, in Bucharest, at the beginning of the ninth decade of the twentieth century, George Emil Palade (a Nobel Laureate in Physiology or Medicine, in 1974) stated that "Functions must be understood in terms of structures; structures must be understood in terms of chemistry". This is the view of an ultrastructural morphologist and a top electronmicroscopist, an opinion that keeps its value until today. There are reciprocal relationships between cell functions, organization, and molecularity. As in a virtuous circle. Under this view, we may, or have to place our concept of cell identity. A cell proves its identity by its function and behavior. Its function (we mean behavior of that cell) is due to its organization.

However, its organization is governed by the molecular composition of its morphological elements. In fact, this is the wisdom in the fundamental understanding of life (a balanced mix of sophia and phronesis). That is the wisdom we have to apply in our effort to define cell identity and to determine the identity of a specific cell (a specific cell in terms of individual identity).

\section{Future challenges}

Our essay presented an opinion regarding how to understand the concept of identity in cell biology, trying to use philosophical opinions related to the term "identity". Other approaches are possible in analyzing and understanding this versatile concept of identity, firstly in a very wide view, and, secondly, for the concept of cell identity. In our opinion, a much broader, interdisciplinary approach is necessary in order to clarify such a complicated task. For example, the concept of identity could be also analyzed in terms of singularity theory from mathematics, trying to clarify it, but this overcomes our ability. We will keep the debate, in this journal, addressing an open invitation to experts capable of analyzing the identity of a cell from the singularity theory view, or from other perspectives. Therefore, the cell identity issue is not a matter of biology only, but needs a multidisciplinary approach to overcome the criticism that "investigations into biological individuality have often been done in relative isolation from other domains which have produced interesting work on individuality" (Pradeu, 2016). In fact, cell identity is not a challenge for biologists and physicians only, but a topic of meditation for philosophers in philosophy of biology, or even metaphysics.

Welcome to cell identity debates! 


\section{Acknowledgements}

Professional editing, linguistic and technical assistance performed by Irina Radu, Individual Service Provider, certified translator in Medicine and Pharmacy (certificate credentials: series E no. 0048).

\section{Funding}

Funded by Ministry of Education and Research in Romania, under Program 1 - The Improvement of the National System of Research and Development, Subprogram 1.2 -Institutional Excellence - Projects of Excellence Funding in RDI, Contract No.7PFE/16.10.2018

\section{References}

Anderson DJ, Zalta EN (2004). Frege, Boolos, and Logical Objects. J Philos Log. 33(1):1-26. doi:10.1023/b:logi.0000019236.64896.fd

\section{Bhattacharyya SN, Habermacher R, et al. (2006)}

Stress-induced reversal of microRNA repression and mRNA P-body localization in human cells. Cold Spring Harb Symp Quant Biol.71:513-21. doi: 10.1101/sqb.2006.71.038

Boolos G (1990) The standard of equality of numbers. In G. Boolos (ed) Meaning and method. Essay in honor of Hilary Putnam. Cambridge: Cambridge University Press, ISBN 0-521-36083-8

Canguilhem G (1978) On the normal and the pathological. Dordrecht: D. Reidel Publishing Company, ISBN: 90-277-0907-6

Canguilhem G (1994) A vital Rationalist. Selected writings form Georges Canguilhem. New York: Zone Books, ISBN: 0-942299-72-8

Charles Richard JL, Eichhorn PJA (2018) Platforms for Investigating LncRNA Functions. SLAS Technol. 23(6):493-506. doi: 10.1177/2472630318780639

Du XH, Wei H, et al. (2020) Gene expression regulations by long noncoding RNAs and their roles in cancer. Pathol Res Pract. 16:152983. doi: 10.1016/j.prp.2020.152983.

Filipowicz W (2005) RNAi: the nuts and bolts of the RISC machine. Cell. 122(1):17-20. doi: 10.1016/j.cell.2005.06.023

Frege G (1950) The foundations of arithmetic, Trans. J.L Austin. Oxford: Basil Blackwell.
Fujimoto T, Parton RG (2011) Not just fat: the structure and function of the lipid droplet. Cold Spring Harb Perspect Biol. 3(3):a004838. doi: 10.1101/cshperspect.a004838

Greenstein RA, Al-Sady B (2019) Epigenetic fates of gene silencing established by heterochromatin spreading in cell identity and genome stability. Curr Genet. 65(2):423-428. doi: 10.1007/s00294018-0901-1

Greenstein RA, Jones SK, Spivey EC, et al (2018) Noncoding RNA-nucleated heterochromatin spreading is intrinsically labile and requires accessory elements for epigenetic stability. Elife. 7. pii: e32948. doi: 10.7554/eLife.32948

Hnisz D, Abraham BJ,et al. (2013) Super-enhancers in the control of cell identity and disease. Cell. 155(4):934-47. doi: 10.1016/j.cell.2013.09.053

Hull DL (1992). Individual. In E. F. Keller and E. A. Lloyd (eds), Keywords in Evolutionary Biology, Cambridge: Harvard University Press, ISBN-13: 978-0674503137

Huxley A (1947) The Perennial Philosophy. London: Chatto \& Windus.

Khan A, Mathelier A, Zhang X (2018) Super-enhancers are transcriptionally more active and cell type-specific than stretch enhancers. Epigenetics.

13(9):910-922. doi:

10.1080/15592294.2018.1514231

Lamouille S, Xu J, Derynck R (2014) Molecular mechanisms of epithelial-mesenchymal transition. Nat Rev Mol Cell Biol. 15(3):178-96. doi: 10.1038/nrm3758 
Lewin K (1922) Der Begriff der Genese in Physik, Biologie und Entwicklungsgeschichte. Berlin: Springer-Verlag Berlin Heidelberg $\mathrm{GmbH}$, ISBN 978-3-662-24340-4

Locke J (1690) An essay concerning human understanding, Revised ed. Penguin Classics, 1998, ISBN-13: 978-0140434828

Martin S, Parton RG (2006) Lipid droplets: A unified view of a dynamic organelle. Nat Rev Mol Cell Biol. 7:373-378. doi: 10.1038/nrm1912

Nicholson DJ, Dupré J (eds) (2018) Everything Flows: Towards a Processual Philosophy of Biology. Oxford: Oxford University Press, ISBN-13: 9780198779636

Noonan H, Curtis B (2018) Identity, The Stanford Encyclopedia of Philosophy (Summer 2018 Edition), Edward N. Zalta (ed.), [cited February 23, 2020] Available at: https://plato.stanford.edu/archives/sum2018/entries/identity/..

Olson ET (2019) Personal Identity, The Stanford Encyclopedia of Philosophy (Fall 2019 Edition), Edward N. Zalta (ed.). [cited February 22, 2020] Available at: https://plato.stanford.edu/archives/fall2019/entries/identity-personal/.

Pradeu T. (2016) The many faces of biological individuality. Biol Philos. 31: 761-773. doi:

$10.1007 /$ s10539-016-9553-z
Pradeu T. (2018) Genidentity and biological processes. In Daniel J. Nicholson and John Dupré eds. Everything Flows: Towards a Processual Philosophy of Biology. Oxford: Oxford University Press, ISBN13: 9780198779636 . Also available online at: https://www.oxfordscholarship.com/view/10.1093 /oso/9780198779636.001.0001/oso9780198779636-chapter-5

Reinchenbach H (1971) The direction of time. Berkley: University of California Press, ISBN: 0-520-01839-7

St Laurent G, Wahlestedt C, Kapranov P (2015) The Landscape of long noncoding RNA classification. Trends Genet. 31(5):239-51. doi: 10.1016/j.tig.2015.03.007

Tilles JE (1976) Davidson's Criterion of Event Identity. Analysis. 36(4):185-187. doi: 10.2307/3327183

Tomari Y, Zamore PD (2005) Perspective: machines for RNAi. Genes Dev. 19(5):517-529. doi: $10.1101 / \mathrm{gad} .1284105$

Wiggins D (1967) Identity and spatio-temporal continuity. Oxford: Basil Blackwell, ISBN 0-631-10370-8

Wittgenstein L (1958) Philosophical Investigations, Trans. G.E.M. Anscombe. Oxford: Basil Blackwell, ISBN 0-631-11900-0 